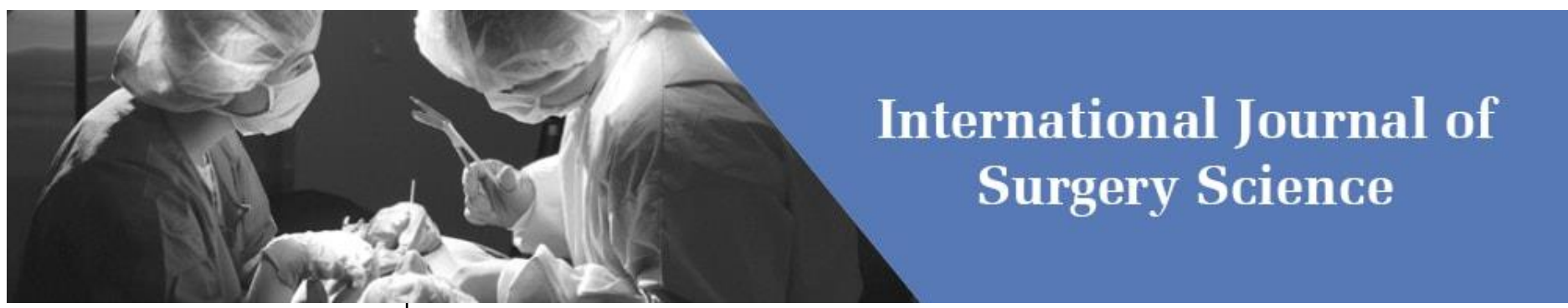

E-ISSN: 2616-3470 P-ISSN: 2616-3462 (C) Surgery Science www.surgeryscience.com 2021; 5(4): 229-235

Received: 18-08-2021

Accepted: 20-09-2021

Syed Balig Ahmed PHD Scholar Maharaj Vinayak Global University Jaipur,

Rajasthan, India
Corresponding Author: Syed Balig Ahmed PHD Scholar Maharaj Vinayak Global University Jaipur, Rajasthan, India

\section{A study to deduce the potency of a structured teaching strategy in preventing pre-administered postoperative complications in patients undergoing abdominal surgery at pre-administered hospitals in the various Hospitals Sawai Madhopur Rajasthan}

\section{Syed Balig Ahmed}

DOI: $\underline{\text { https://doi.org/10.33545/surgery.2021.v5.i4d.791 }}$

\section{Abstract}

Background: Surgery is a substantial specialty of medicine that involves the ways to accelerate a corporeal system to detect, curb, or relieve an illness. Ambroise pares, a 16th-century French surgeon, asserted that surgery was obtained for five reasons. "To, what is unnecessary, to rebuild what has been ruptured, to differentiate what has been insulated, and to fix the deficiencies of the essence." To treat injuries and tragedies, the very first clinical methods were introduced. According to the sample registration system, four billion abdominal surgeries, including ostomies, are performed worldwide each year. Each year, $40 \%$ of the population in India undergoes abdominal surgery. In Rajasthan, $42 \%$ of bowel resections are conducted in private clinics, while $58 \%$ of treatments are conducted in government hospitals.

Methods: Traditionally, evaluative exploration has been divided into four broad phases. It was determined that a quantitative- evaluative strategy was reasonable for this exploration. The current study employed a pre-experimental technique (one group pre and post-test design. research was administered at the Riya Hospital and Jeevan Surgical Hospital in the Sawai Madhopur Rajasthan. study's target population was abdominal surgery patients at Riya Hospital Sawai Madhopur as well as Javeen Surgical Hospital Sawai Madhopur. A sample is a collection of observed variables chosen for the study. The specimens were assigned using a non-probabilistic control sampling procedure established on their availability. The study used an Structured Interview Schedule to elicit data on the knowledge of patients undergoing abdominal surgery.

Results: According to the study, 170 (56.7 percent) of patient populations were Hindus, 110 (36.7 percent) were Muslims, 10 (3.3 percent) were Christians and 10 (3.3 percent) were others. The relationship between post-test knowledge scores respecting the deterrence of selected postoperative difficulties and selected demographic variables for patients undergoing abdominal surgery. Using chi-square (X2) analysis, it was determined that there was a significant correlation between education and knowledge considering the deterrence of selected surgical patients between patients receiving abdominal surgery at the p0.01 level. Using chi-square (X2) analysis, it was determined that there was no correlation between age, ethnic background, faith, profession, annual payment, education level, parental education, place of residence, dietary pattern, lifestyle traits, and citation of patient data post-test mean knowledge prevention and management of selected post-operative health problems among patients receiving abdominal surgery at $p>0.0$.

Conclusion: The research concluded that structured teaching is an effective technique for imparting a progressive to sufficient degree of knowledge about health topics to members of today's society, which places a premium on public health rather than disease treatment.

Keywords: Examine, effectiveness, diverse complications, structured teaching program, abdominal surgery, patients

\section{Introduction}

All through early Greek and Roman humanity, surgery was accomplished by medics or healers,' but was claimed by undereducated hairdressers during the Middle Ages. Although during the 16 th and 17th centuries, surgery was again used in medical jurisdiction. Nowadays, most minimally invasive processes are required in primary care or outpatient settings, owing to improvements in medical intervention and percussion, as well as in anesthesia. 
As per the nationwide degenerative diseases emptying the house, between 60 and 70 million Americans are affected by degenerative diseases. In 1985, digestive illnesses accounted for $13 \%$ of all hospital stays and $16 \%$ of diagnostic procedures in the United States. Diarrhea disorders ( $\$ 4.7$ billion), gallbladder illnesses ( $\$ 4.5$ billion), colorectal cancer ( $\$ 4.5$ billion), liver illnesses ( $\$ 3.2$ billion), and ulcerative colitis diseases $(\$ 4.5$ billion) are the most vital digestive disorders. All surgical procedures carry a few other risks of side effects. Countless situations may occur all through abdominal surgery as well. Clinical symptoms include respiratory symptoms (pneumonia, hepatic encephalopathy, and collapsed lung), circulatory complications (hemorrhage, cardiogenic shock, deep vein thrombosis, and tension pneumothorax), and gastrointestinal difficulties (nausea, puking, acid reflux, tympanites, and immobilized ileus). Wound troubles (wound illness, wound excoriation, scar tissue, and incisional (urinary retention, urinary tract infections). Preoperative pulmonary complications occur at varying rates relying on the sort of surgery and patient-related factors. High abdominal as well as interventional, length of sedation, age, diabetes, smoking history, and fundamental lung infections such as COPD are all risk factors. Additionally, education about potential complications should be administered to the client as well as those who may aid caregivers at home. Evaluating and rerecognizingealth risks for comorbidities are critical for early intervention, which can result in improved outcomes and faster wound healing. Over 4 million retroperitoneal medications are given annually in the United States. Abdominal surgery patients are at a heightened threat of expanding pulmonary difficulties. Postoperative pulmonary difficulties arise to be attributed to a disruption of the respiratory muscles' normal activity. In 2016, the occurrence rate of overall bowel resections in Riya Hospital and Jeevan Surgical Hospital Sawai Madhopur 547. Whereas in Sawai Madhopur Private Hospital was 654 . The objective of this survey was to analyze the structure of appendectomy health problems in adults aged 16 years. An aggregate of 199 patients was included in the research. 58 patients $(29 \%)$ had postoperative complications; 8 (4\%) were conceded to the surgery's critical care unit. One patient died $(0.5 \%)$, nine patients required reoperation due to a postoperative complication $(4.5 \%)$, and 26 patients required readmission (13 percent). According to a study conducted over the last 15 years, the rate of postoperative pulmonary difficulties attending abdominal systems such as splenectomy, gastrectomy, vagotomy, and partial resection of the intestinal tract, total colon resection, appendectomy, and herniorrhaphy is rising in both males and females. In 1990, hospitals run by the Ministry of Health $(\mathrm{MOH})$ were overpopulated with victims. On surgical floors, this overcrowding was relatively obvious. Two factors contributed to the overcrowding: the high incidence of enrollment and the length of stay of some patients. The most common reasons for prolonged hospitalization were postoperative complications and patient anxiety about their wounds. Both of these complications can be avoided or minimized with a preoperative patient education program. Established on a survey of the literature and the investigator's expertise in the field of a registered nurse, she discovered that abdomen treatments are complicated events that result in a variety of health dilemmas, most notably respiratory, gastrointestinal intestinal, and wound complications due to anesthesia and the patient's ignorance of intricacies and lack of knowledge regarding preventive measures. The investigator wishes to investigate the impact of a structured education strategy on patients undergoing abdominal surgery's knowledge considering the prevention of selected postoperative difficulties.

\section{Methods}

Traditionally, evaluative exploration has been divided into four broad phases. Identifying and defining the program's objectives, creating a metric to assess whether or not those objectives have been met Collecting data interpretation about the objective; the difference between the average and node measurements in data analysis represents the effect of independent variables. Given the nature of the research problem and the project's objectives, it was determined that a quantitative- evaluative strategy was reasonable for this exploration. Administering a pre-test, executing a Structured Teaching Program instantly, and then administering a post-test to a similar faction after seven days. Attributed variables include age, gender, religion, education, invasion, family status, annual payment, family type, nutritional status, lifestyle traits, residence, and source of information. The research was administered at the Riya Hospital and Jeevan Surgical Hospital in the Sawai Madhopur Rajasthan, a 300-bed hospital. The study's target population was abdominal surgery patients at Riya Hospital Sawai Madhopur as well as Javeen Surgical Hospital Sawai Madhopur. The study sampled 300 patients aged 20 to 60 years from both sexes who were accepted for bowel resections at a Riya Hospital and Javeen Surgical Hospital in Sawai Madhopur. The specimens were assigned using a non-probabilistic control sampling procedure established on their availability. Objective-type questions with options were chosen to assess patients' knowledge before and following the execution of the Centralized Education Program. The study used an interview schedule to elicit data on the knowledge of patients undergoing abdominal surgery in Riya Hospital and Javeen Surgical Hospital in Sawai Madhopur regarding the prevention of selected complications. It is divided into two sections: Part I contains questionnaire items about demographic data. Part II contains questions about the prevention of certain postoperative complications. To develop the Structured Teaching Programme, a blueprint of goals and material relating to knowledge regarding the prevention of selected postoperative complications was preferred. The Structured Teaching Component covers general information about the respiratory organs, their causes, clinical characteristics, and protection of respiratory disorders. General information about the gastrointestinal organs, their causes, clinical characteristics, and methods for preventing gastrointestinal complications. General information about the skin and wounds, their causes, clinical characteristics, and how to prevent wound complications following abdominal surgery. The initial draught was created using the goals, set of criteria review, review paper, and expert analysis. The following primary factors were considered when developing the Structured Teaching Programme: the samples' literacy level. The Structured Teaching Program's title was "prevention of selected postoperative complications." It contained an introduction, broad and detailed objectives, content, and references. The Systematic Instructional Curriculum was designed to increase participants knowledge of how to prevent certain postoperative complications. The questionnaire was structured for six months, from $9 / 12 / 2017$ to $19 / 06 / 2018$. The investigator gathered preand post-test data and oversaw the implementation of the Structured Teaching Program. Before the data collection procedure, the purpose of the data collection was clarified and study subjects verbally consented. Pre-testing was performed on four to five patients per day in the surgical wards of the Riya Hospital Sawai Madhopur and Jeevan Surgical Hospital Sawai Madhopur districts, using a structured interview schedule. A structured teaching session lasting 60 minutes was conducted. 
Every day, each group receives between four and five patients. Flipcharts and flashcards were used as visual aids. Following the completion of the Systematic Education Curriculum, a post-test using the same validated interview and interview schedule was administered on the seventh day to deduce the effectiveness of the Systematic Education Curriculum on patients' knowledge regarding the deterrence of selected postoperative complications. Post-tests were conducted on patients' review dates and at their convenience to avoid dropout.

\section{Results}

According to the overall population of subject areas in Table - 1, 118 (39.3 percent) patients were between the ages of 21-30 years, 96 (32.0 percent) individuals were between the ages of $31-40$ years, 48 (16.0 percent) individuals were between the ages of 41-50 years, and 38 (12.7 percent) individuals were between the ages of 51-60 years.

Table 1: Regularity and proportion of the casualties undergoing abdominal surgeries according to their age.

\begin{tabular}{|c|c|c|}
\multicolumn{2}{|c}{} & $\mathrm{N}=300$ \\
\hline Age in Years & Frequency & Percentage \\
\hline $21-30$ years & 118 & 39.3 \\
\hline $31-40$ years & 96 & 32.0 \\
\hline 41-50 years & 48 & 16.0 \\
\hline 51-60 years & 38 & 12.7 \\
\hline Total & 300 & 100 \\
\hline
\end{tabular}

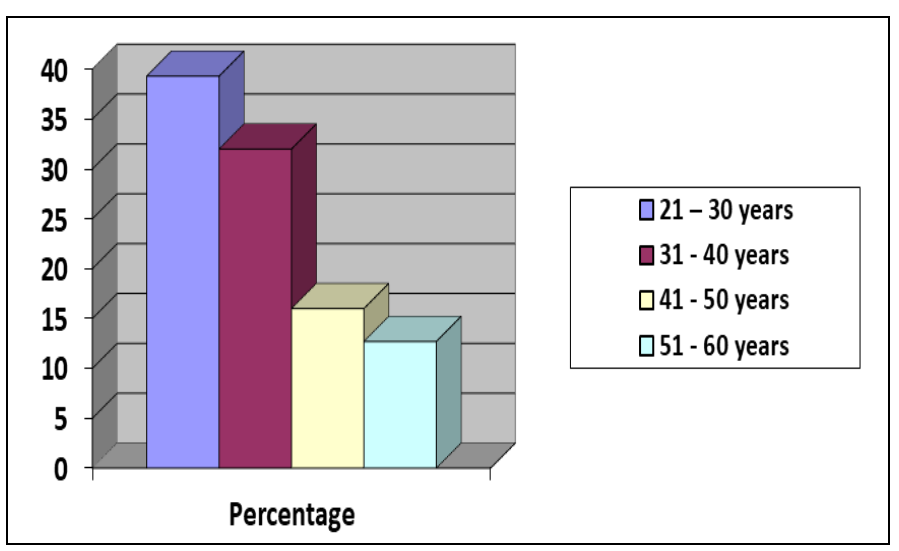

Fig 1: Column diagram representing percentage dispersion of the casualties withstanding abdominal surgeries according to their age.

\section{Age of Year}

Table 2: Frequency and percentage distribution of samples according to their religion

\begin{tabular}{|c|c|c|}
\multicolumn{1}{c|}{} & $\mathrm{N}=300$ \\
\hline Religion & Frequency & Percentage \\
\hline Hindu & 170 & 56.7 \\
\hline Muslim & 110 & 36.7 \\
\hline Christian & 10 & 3.3 \\
\hline Others & 10 & 3.3 \\
\hline Total & 300 & 100 \\
\hline
\end{tabular}

As per table - 2, 170 (56.7 percent) of individuals are Hindus, 110 (36.7 percent) were Muslims, 10 (3.3 percent) were Christians and 10 (3.3 percent) were others

According to the data in Table -3 , the majority of subjects in pretest 210 (70 percent) possessed insufficient knowledge, 90 (30 percent possessed moderate knowledge, and none possessed adequate knowledge interventions for the prevention of selected postoperative complications.

Table 3: Frequency and percentage distribution of knowledge level of patients undergoing abdominal surgeries in the pre-test.

\begin{tabular}{|c|c|c|}
\hline \multirow{2}{*}{ Level of knowledge } & \multicolumn{2}{|c|}{$\mathrm{N}=300$} \\
\cline { 2 - 3 } & Frequency & Percentage \\
\hline Inadequate (below 50\%) & 210 & 70 \\
\hline Moderate (51 - 75\%) & 90 & 30 \\
\hline Adequate (above 75\%) & - & - \\
\hline Total & 300 & 100 \\
\hline
\end{tabular}

The information in Figure No.4 illustrates the pre-test knowledge scores by aspect. 232 (77.3 percent) had insufficient knowledge about gastrointestinal complications, while $68(22.7$ percent) had moderate knowledge. $228(76 \%)$ of the breathing co morbidities component lacked adequate knowledge. 68 (22.7 percent) had an appropriate level, 198 had insufficient knowledge, 101 (33.6 percent) had moderate knowledge, and 1 (0.04 percent) had adequate knowledge. 210 (70\%) had insufficient knowledge, 90 (30\%) had an appropriate level, and none had sufficient knowledge interventions for the prevention of selected clinical symptoms.

Table 4: Components wise distribution of frequency and percentage of pretest

\begin{tabular}{|c|c|c|c|c|c|c|}
\hline \multirow{3}{*}{ Aspects of knowledge } & \multicolumn{6}{|c|}{ Level of knowledge } \\
\hline & \multicolumn{2}{|c|}{ Inadequate (below 50\%) } & \multicolumn{2}{|c|}{ Moderate $(51-75 \%)$} & \multicolumn{2}{|c|}{ Adequate (above 75\% } \\
\hline & Frequency & Percentage & Frequency & Percentage & Frequency & Percentage \\
\hline Respiratory complications & 228 & 76.0 & 72 & 24.0 & - & - \\
\hline Gastrointestinal complications & 232 & 77.3 & 68 & 22.7 & - & - \\
\hline Wound complications & 198 & 66.0 & 101 & 33.6 & 1 & .04 \\
\hline Overall & 210 & 70.0 & 90 & 30.0 & - & - \\
\hline
\end{tabular}

Table 5: Mean, standard deviation, and paired value of pretest and post-test knowledge level of patients undergoing abdominal surgeries

\begin{tabular}{|c|c|c|c|c|c|c|c|}
\hline \multirow{2}{*}{$\begin{array}{c}\text { Sl. } \\
\text { No. }\end{array}$} & \multirow{2}{*}{ Aspects of knowledge } & \multicolumn{2}{|r|}{ Pretest } & \multicolumn{2}{|r|}{ Post-test } & \multirow{2}{*}{ Paired 'to value } & \multirow{2}{*}{ P-value } \\
\hline & & Mean & Standard deviation & Mean & Standard deviation & & \\
\hline 1. & Respiratory complications & 5.07 & 2.55 & 11.6 & 2.042 & 19.43 & $\mathrm{P}<0.01$ \\
\hline 2. & Gastrointestinal complications & 4.98 & 2.72 & 8.9 & 0.937 & 14.74 & $\mathrm{P}<0.01$ \\
\hline 3. & Wound complications & 5.96 & 1.65 & 10.18 & 1.84 & 13.37 & $\mathrm{P}<0.01$ \\
\hline 4. & Over All & 16.15 & 4.657 & 30.7 & 5.387 & 20.56 & $\mathrm{P}<0.01$ \\
\hline
\end{tabular}

*Significant at 0.01 level. 
According to the preceding table, the mean significance for respiratory difficulties was 5.07 in the pretest, with a mean difference of 2.55. Difficulties of the gastrointestinal tract had a mean of 4.98 and a standard divergence of 2.72. Wound difficulties occurred on regular at a rate of 5.96, with a mean discrepancy of 1.65 . The mean of respiratory difficulties posttest was 11.6 with a mean difference of 2.042. Difficulties of the gastrointestinal tract were on average 8.9, with a standard deviation of 0.937 . For wound difficulties, the mean score was 10.18 , with a mean discrepancy of 1.84 . The paired value for respiratory difficulties was $19.43,14.74$ for gastrointestinal difficulties, and 13.37 for wound difficulties. Before the test, the median importance was 16.15 , with a mean discrepancy of 4.657. The contrary following the test was 30.7, and the standard divergence was 5.387. The overall paired value for pre-tested has a value of 20.56 at the p0.01 level.

Table 6: findings of association between post-test level of knowledge score regarding prevention of selected postoperative complications with their selected demographic variables among patients undergoing abdominal Surgeries.

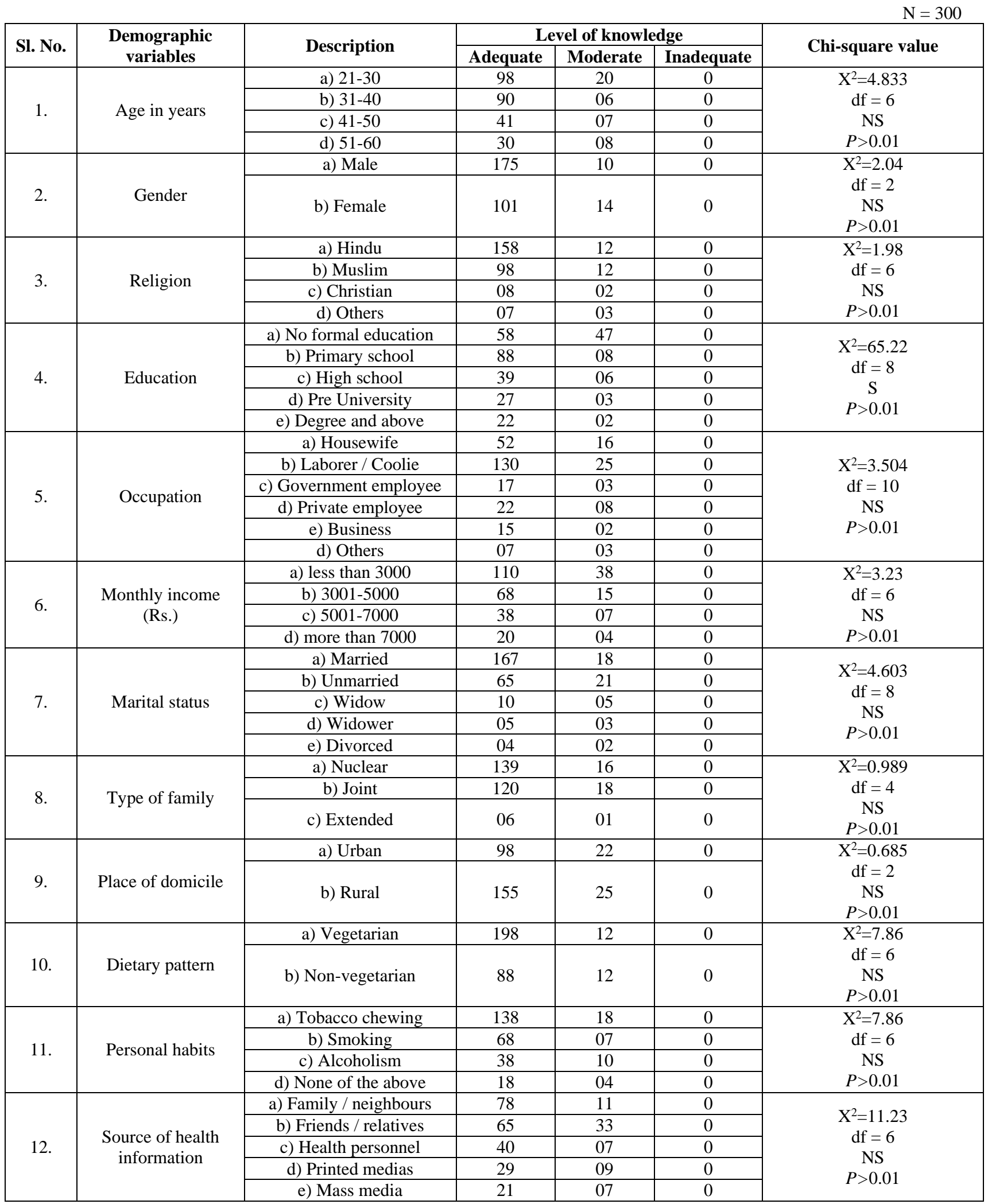


It was determined that there was a significant correlation between education and knowledge considering the deterrence of selected surgical patients between patients receiving abdominal surgery at the p0.01 level. Using chi-square (X2) analysis, it was determined that there was no correlation between age, ethnic background, faith, profession, annual payment, education level, parental education, place of residence, dietary pattern, lifestyle traits, and citation of patient data post-test mean knowledge prevention and management of selected post-operative health problems among patients receiving abdominal surgery at $p>0.0$.

\section{Discussion}

Most of 118 (39.3 percent) patients were between the ages of 21 and 30, 96 (32.0 percent) patients were between the ages of 31 and 40, 48 (16.0 percent) patients were between the ages of 41 and 50, and 38 (12.7 percent) patients were between the ages of 51 and 60. According to the study, 185 (61.7 percent) of patients were male, while 115 (38.3 percent) were female. According to the study, 170 (56.7 percent) of sick people were Hindus, 110 (36.7 percent) were Muslims, 10 (3.3 percent) were Christians 10 (3.3 percent) were others. Pre-test knowledge of the majority of patients regarding the prevention of selected postoperative pain was insufficient 210 (70.0 percent), whereas the majority of subjects had adequate post-test knowledge 215 (71.7 percent). The post-test mean scores were 30.7 with a standard deviation of 5.387, which is broadly greater than the average pretest education level of 16.15 with a standard deviation of 4.657. Additionally, the computed paired to the value of 20.56 is enormous than the table value of 2.62, indicating that the intensive educational method was successful at the P0.01 level. The chi-square test was utilized to deduce the federation between post-test understanding scores and appointed demographic variables in patients suffering abdominal surgery. The outcomes demonstrate that there is a strong relationship between education level and schooling at the p0.01 level, but no affiliation between education level and age, sex, faith, profession, annual payment, or relationship status. A randomized examination was performed to ascertain postoperative difficulties. 411 surgeries were performed in total. 258 (62.8 percent) of the procedures were discretionary, while 153 (37.2 percent) were a crisis. Hernia repair was accomplished on 92 (22.4 percent) casualties. 64 patients $(15.6 \%)$ had an appendectomy, and 54 had a cholecystectomy (13.2 percent). Postoperative pyrexia was the most frequently observed complication in 75 (18.2 percent) of patients. Postoperative revulsion and puking occurred in 48 (11.6 percent) of the patient population, chronic wounds occurred in 47 (11.4 percent) of the patient population, and respiratory infections occurred in 29 (7.0 percent) of the patient population. a randomized clinical examination was conducted to deduce how to deter and govern difficulties following colon inters auction for destructive esophagus ulcers. This study included 85 sufferers with caustic esophageal burns. Seven of fourteen patients (8.5 percent to 17.1 percent) died as a result of medical diseases such as inhaled pneumonia, fright colon necrosis, abdomen dehiscence, and swallow and respiratory function harm. 25 individuals $(30.1 \%)$ with benign growths were published for treatment and followup. The study's conclusions implied that the overall disorder rate for colon procedures was $20 \%$ and for small bowel operations was $11 \%$. According to the study's findings, the incidence of wound infection following colorectal surgery is considerably higher than that following small bowel procedure. Preoperative respiratory exercise instruction helps reduce pulmonary complications and hospital stay. People with deep, copious mucus may benefit from postoperative cardiovascular and cough exercises. Pre-operative safety is a key component of the preoperative order to prepare a patient for a surgical procedure that a nurse provides. Preoperative education aids in the reduction of emotional stress and the prevention of complications. The nurse can enlighten, assist, and interact with adult surgical patients program introduces to achieve efficient preoperative therapeutic teaching. This study sought to determine the efficacy of both formally and informally preoperative education. For structured preoperative instruction, 49 subjects were chosen. The investigator served as the main instructor, and patients' abilities to function breaths, coughing, and exercises were assessed using a logbook. As measured by respiratory function, preoperative structured instruction significantly improved patients' ability to deep breathe and cough postoperatively.

\section{Conclusion}

According to the study's findings, the majority (70\%) of research participants had insufficient knowledge before the test, while only $30 \%$ of research participants had an appropriate let he commencement of the organized education curriculum, no subject possessed adequate knowledge. However, after implementing the structured teaching program, 85 (28.3 percent) of them demonstrated moderate knowledge, 215 (71.7 percent) demonstrated adequate knowledge, and none demonstrated insufficient knowledge. The average post-exam results for all components are significantly greater than the standard pre-test scores at the P0.01 level. The overall mean posttest score of 30.7 is greater than the mean pretest score of 16.15 , indicating that the intensive educational system is successful, a finding that is statically important at the P0.01 level. At the P0.01 level, a substantial correlation exists between post-test education level and schooling in the current study. At the $P>0.01$ level, no substantial relationship is observed between age, sex, faith, profession, annual payment, relationship status, parental education, eating choices, personnel lifestyles, and source of knowledge. The outcome indicates that the level of knowledge of the 'patients' improved following the implementation of an organized education curriculum on the deterrence of selected postoperative difficulties. The research concluded that structured teaching is an effective technique for imparting a progressive to sufficient degree of knowledge about health topics to members of today's society, which places a premium on public health rather than disease treatment.

Limitations: The method is restricted to people aged 20 to 60 years who are accepted to the Sawai Madhopur Riya Hospital and Jeevan Surgical Sawai Madhopur. The study's findings are limited to Sawai Madhopur Riya Hospital and Jeevan Surgical Sawai Madhopur. This study will not include a control group. Six weeks will be spent on the study.

Recommendations: The following recommendations are made in the illumination of the study's findings. To generalize the findings, a large pattern with a larger sample can be used. For effective comparison; a similar experiment with a comparison group can be conducted. Comparative studies can be conducted among private and public hospitals, as well as between rural and urban regions. The same research can be adjusted to meet the unique needs of the hospital.

The study's consequences: the study's findings can be applied to the following areas. Nursing practice in the clinic "Prevention is preferable to treatment, and public health is held in high 
regard." While nurses work in a variety of fields, their primary goal is to promote the health of all patients. The nursing staff is transitioning to an era of evidence-based nursing practice, in which they integrate cutting-edge findings from biological and behavioral sciences into their practice to assist people from diverse cultural backgrounds in adopting active diets. Nursing professionals who work in a wide variety of medical wards will be able to practice and gain knowledge about preventing certain postoperative symptoms in patients undergoing abdominal surgery. Professional nurses faced by healthcare settings came in contact with a significant number of people who are afflicted with postoperative breathing, gastrointestinal, injury, urinary, and cardiovascular problems, to name a few. In clinical settings, postoperative complications are the leading cause of death. As a result, nurses should encourage patients about the importance of avoiding postoperative complications. This will benefit patients by assisting them in promoting and safeguarding their health. The objective of this research is to expand the fitness status of patients undergoing abdominal surgery and to prevent further postoperative complications. Complications can be avoided with postoperative breathing exercises, coughing, transforming, leg workouts, diathermy, lung physical therapy and vapor ingestion, a proper diet, and proper wound care.

Education in nursing: Nurses who focus their careers on preventive medicine will have a very vibrant and constructive future. Nurses must stay current on emerging technologies, approaches, and techniques. Postoperative complications are becoming more prevalent nowadays as a result of a lack of awareness and ignorance. Thus, education on the prevention of selected postoperative complications assists nursing personnel in preventing injuries and avoiding such difficulties through inservice and continuing education, as well as the inclusion of additional preventive aspects in the nursing curriculum. Administration of nursing the nurse superintendent should participate in the development of health policies and protocols for preventing postoperative complications such as breathing, gastrointestinal, cardiovascular, urinary, and wound complications. Nursing administrators should educate nurses on postoperative complications such as respiratory, gastrointestinal, and wound complications. Nursing investigation Research enables health care providers to formulate a comprehensive approach to problem-solving in addition to supporting strategies to promote individual health. The nurse should be able to specify and confirm the concept through research. Evidence-based practice is rapidly gaining popularity due to its factually and substantively sound results. These studies produce fruitful outcomes that are extremely beneficial in resolving emerging issues and developing nursing protocols. Much more research is needed on interventions that target individuals rather than group stereotypes. Promoting health methods and preventing disease are frequent research topics. Since the modern population is concerned with avoiding postoperative complications. Nurse researchers can research postoperative complications prevention. This chapter discussed the study's conclusion, limitations, recommendations, and implications.

\section{References}

1. History of surgery. http;//does.google.com

2. Origin of surgery.www.wikipedia,the free encyclopedia.com

3. Phipps.shafers medical surgical nursing. 7th ed. B I publication pvt.Ltd.New Delhi, 494.

4. Brunner, Suddharth. Medical and surgical nursing 11th ed., 2009.
5. Demographic gastroenterological surgery. Jop 2006;7(6):608-15.

6. Text book of clinical surgery. 1st ed. 1994.

7. Potter, Perry. Fundamentals of nursing. 6th ed. Mosby publication. 2006, 1636-37.

8. Baker PJ. Post operative atelectasis. Nursing digest. 5:42. spring 1977.

9. Erick HJ et al. Pulmonary complication and morbidity and mortality 1984.

10. Luckman and Sorensen. Medical surgical nursing. A psychological physiological approach. $2^{\text {nd }}$ ed. WB Saunders Company 417.

11. Lewis. Text book of medical and surgical nursing. 8th ed. W.B. Saunders Company 318, 320-22.

12. Bailey, Love's. Short practice of surgery. 24th ed. Holder Arnold publishers Ltd. 1092, 1216-17.

13. Sr. Nancy. Principle sand practice of Nursing. 3rd ed. NR publishing house. Indore 45.

14. Laurie Barelay. Pulmonary complication of major abdominal surgery may be increasing in US Hospital Medicine 2007;49:23-25.

15. www.yahoo.com.Abdominal surgery incidence rate.

16. Simpson J, Samaraweera AP, Sara RK, Lobo DN. Aute appendicits. A benign disease. J. Simpson@nottingham.ac.uk.

17. Wacha H. Wound infections in abdominal surgery. Etiology. Riskfactors. Antibiotics prophylaxis 2007;132(5):400-10.

18. Akbar MA. Text book of surgery. $2^{\text {nd }}$ ed. Paras medical publishers. Hyderabad 2001.

19. Asiam T, Masood R, maher M. Early complications following pancreaticoduodenectomy, 2005, 15.

20. Rafique M. Information on post operative complications 2001;42(1):612-16.

21. Black Joice M. Medical Surgical Nursing. 6th ed. Harcourt Aasia Publications WB Saunders Company. New Delhi 423.

22. Oetker Black. Jones Estok. et al. Pre-operative teaching. May; 2003. Vol 3; 252-66.

23. Moroney's. Surgery for Nurses. 16th ed. published by Elsevier. New Delhi 26-27.

24. Finn KL. Post operative Ambulation. Critical care updates 7:22-26, 198.

25. Lippincott. Manual for nursing. 2nd ed. Lippincott Company 2002.

26. Dalayon AP. Components of pre-operative patient teaching in Kuwait 1990.

27. Barbara Kozier. Text book of fundamentals of nursing. 7th ed. Published by Dorling Kindersely (India) Pvt. Ltd. 2008, 940.

28. Wesky Ruby L. Nursing Theories and models. 2nd ed. Springhouse publication Pennylvania 1995, 02-85.

29. Basavanthappa BT. Nursing Research. 1st ed. published by Jaypee brothers. New Delhi 1998-93.

30. Masood, Jawaid Zubia Masood. Syed Abdulliah Igbal. Post operative complications in general surgical ward of a teaching hospital. Paks Med science 2006;22:2171-75.

31. Mathew JT, D' Souza GA, Kilpade AB. Respiratory complications in post operative patients 1999;47(1):1086-8.

32. Lausten GS. Engell HC. Early post operative complications in abdominal surgery 1984;150(6):457-61.

33. Dronkers J, Veldman A, Hobrg E, Van der wall C, Van meeteren N. Effe3ct of prevention of pulmonary complications after upper abdominal surgery 
2008;22(2):134-42.

34. Mimica Z, Pogorelic Z, Perkoz Sersen D, et al. Effect of surgical incision on pain and respiratory function after abdominal surgery 2007;54(80):2216-20.

35. West wood $\mathrm{K}$, Griffin $\mathrm{M}$, Roberts $\mathrm{K}$, et al. Incentive spirometry decreases respiratory complications following major abdominal surgery 2007;5(6):339-42.

36. Pasquinia Martin $\mathrm{R}$, Tramer MD, Jean Max et al. Prevention of respiratory complications after abdominal surgery 2007;14(6):432-36.

37. Patrick Pasquina et al. Respiratory Physiotherapy for prevention of pulmonary complications after abdominal surgery. Patrick.Pasguina @ hcuge.ch.

38. Bartlet RH, et al. Respiratory measures for prevention of pulmonary complications. Jama 2006;224:1017.

39. Deodhar SD, Mohite JD, Shirahatti RG, Joshi G. Preoperative prophylaxis measures for prevention of pulmonary complications after upper abdominal surgery 2006;(37):88-92.

40. Morran CG, Finlay IG, et al. chest physiotherapy for prevention of pulmonary complications after major abdominal and thoracie surgery 2005;4(7):419-26.

41. Celli BR, Rodriguez KS, Snider Gl. Effectiveness of incentive spirometry and deep breathing exercise on prevention of respiratory complications after abdominal surgery 2005;6(7):917-926.

42. Mackay MR, Ellis Johstonc E. Physiotherapy after open abdominal surgery in high risk patients 2005;51(3):151-9.

43. Wiklander O, Norlin V. Examine the effect of incentive spirometry for prevention of post operative pulmonary complications 2003;58(2):612-16.

44. Deng B, Wang RW, et al. prevention and management of complications after colon inter positive for corrosive esophageal burns 2008;21(1):57-62.

45. Gibbs L. Continuous irrigation with suction minimizes pancreatic leakage 2006;7(4).

46. Wu LH, Zhang W. Prevention and treatment of complications after duodenopancreatectomy. 2005;25(4):461-3.

47. Thompson HJ. Efficacy of ginger for the prevention of post operative nausea and vomiting. Journal of advanced nursing 2000;29(5):1130-1136.

48. Eu KW, Lim et al. Clinical outcome and bowel function following total abdominal colectomy and ileonectal anastomosis 1998;41(2):215-8.

49. Wick EC, Gibbs L, Indorf LA, Varma MG, Garcia J. Implementation of quality measures to reduce surgical site infection in colorectal patients Epub 2008;51(7):1004-9.

50. Ahmad S, Musft TS, Zafar A, Akbar I. Consenative management of mesh site infection in ventral hernia repair 2007;19(4):75-7.

51. Zhebrovskil VV, Krirorut et al. Optimization inpatient underwent abdominal cavity organ surgery 2006;(8):32-3.

52. Rogliani M, Silvi E, Labardi L, Maggiuilli F, Cervelli V. Effect of obesity on the incidence of complications after abdominoplasty 2005. PmID- 16929206.

53. Alphonsa A. Evaluation of programme implemental to reduce surgical site wound infection in an acute care hospital in India 2004;6(2):112-4.

54. King I, Tarsitano B. The effect of structured and unstructured pre-operative teaching. Nurs Res 2004;31(6):324-9.

55. Garrant Son S. Benefits of pre-opertive information programmes nurs stard. 2004;18(47):33-7.
56. Kroenke K, Lawrence VA, et al. Pre-operative leaching among patients undergoing abdominal surgery 2004;30(2):112-4.

57. Posed N. Pre-operative teaching in the clinicals. Journal of nursing. Staff development 2002;14(1):52-56.

58. Rayder MA. Effects of structured and unstructured preoperative teaching of deep breathing and coughing exercise 2001;42(2):52-56.

59. Dziurbeyko MM, Larkin JC. Pre operative teaching regarding chest physiotherapy 2001;52(4):405-407.

60. Lookinland S, Pool M. Study effect of method of preoperative education in women. AoRNJ. 1998;67(1):203-8, 210-3.

61. Schrakel DC. Pre admission structured education 1998;32(2):192-8.

62. Pellino H. Effects on pre operative teaching 1998;7:22-26.

63. Miskovic A, Luum AB. British Journal of anesthesia, 118:03. 2017;118(03):317-334.

64. Kalpana Vinod Kelkar. Post-operative pulmonary complications after non-cardiothoracic surgery. Indian J Anaesth 2015;59(9):599-605. 